\title{
Successful case of veno-venous extracorporeal membrane oxygenation in an abdominal trauma patient$$
\text { - A case report - }
$$

Received April 30, 2018

Revised 1st, June 21, 2018 2nd, July 14, 2018

Accepted July 16, 2018

\author{
Corresponding author \\ Ji Yeon Kim, M.D., Ph.D. \\ Department of Anesthesiology and \\ Pain Medicine, Ilsan Paik Hospital, \\ Inje University College of Medicine, \\ 170 Juhwa-ro, Ilsanseo-gu, Goyang \\ 10380, Korea \\ Tel: 82-31-910-7160 \\ Fax: 82-31-910-7184 \\ E-mail: jy67925@naver.com \\ ORCID \\ https://orcid.org/0000-0002-4686-5638
}

\section{Jun Hyun Kim, Ji Yeon Kim, and Sunghyeok Park}

Department of Anesthesiology and Pain Medicine, Ilsan Paik Hospital, Inje University College of Medicine, Goyang, Korea

A 37-year-old male visited the hospital with multiple trauma after traffic accident. Fractures of ribs, left femur, and right humerus and spleen rupture with hemoperitoneum were founded on image studies. He was moved to operation room and general anesthesia was performed for splenectomy. During the operation, excessive high peak inspiratory pressure was observed. After abdominal closure, hypoxia, hypercapnia, and respiratory acidosis were worsened. Veno-venous extracorporeal membrane oxygenation (ECMO) was initiated after the operation. Status of the patient were improved after the application of ECMO. The patient was discharged without significant complication. Despite of several limitations in applying ECMO to patients with abdominal compartment syndrome (ACS) and multiple trauma, severe pulmonary dysfunction in ACS patients may be rescued without open abdomen treatment.

Keywords: Adult respiratory distress syndrome; Extracorporeal membrane oxygenation; Hemoperitoneum; Intra-abdominal hypertension; Multiple trauma.
The intra-abdominal pressure (IAP) is generally 5-7 $\mathrm{mmHg}$. An increase of the pressure inside the abdominal cavity can cause a decrease in organ perfusion. IAP exceeding $12 \mathrm{mmHg}$ is known as intra-abdominal hypertension (IAH), and IAP in excess of $20 \mathrm{mmHg}$ accompanied by new organ dysfunction is called acute abdominal compartment syndrome (ACS).

Previous case reports suggest that ACS can complicate extracorporeal membrane oxygenation (ECMO) for several reasons $[1,2]$.

We report a case of respiratory failure in a multiple trauma patient with ACS that was successfully managed using venovenous (VV) ECMO.

\section{CASE REPORT}

A 37-year-old obese male (height $176 \mathrm{~cm}$; weight $110 \mathrm{~kg}$; body mass index $35.5 \mathrm{~kg} / \mathrm{m}^{2}$ ) with no specific past medical history visited the emergency room following a motorbike traffic accident. His consciousness at the time of arrival was clear. His blood pressure was 100/50 $\mathrm{mmHg}$, heart rate was 82 beats/min, and oxygen saturation was $99 \%$. Two hours later, the patient's blood pressure decreased to $75 / 43 \mathrm{mmHg}$ and the heart rate increased to 130 beats/min. Norepinephrine infusion was initiated. Approximately $8,000 \mathrm{ml}$ of the crystalloid solution was administered and 8 units of packed red blood cells were transfused. Imaging showed a right rib fracture, left femur open fracture, and left humerus fracture. Spleen rupture accompanied by hemoperitoneum was ob-

This is an Open Access article distributed under the terms of the Creative Commons Attribution Non-Commercial License (http://creativecommons.org/licenses/by-nc/4.0) which permits unrestricted non-commercial use, distribution, and reproduction in any medium, provided the original work is properly cited. 
served on abdominal computed tomography (Fig. 1). The decision was made to perform emergency splenectomy for spleen rupture. The patient's consciousness worsened to deep drowsiness. To prevent aspiration of gastric contents, tracheal intubation was performed using an $8.0 \mathrm{~mm}$ ID endotracheal tube.

Upon arrival in the operation room, the patient's blood pressure was 134/66 $\mathrm{mmHg}$, heart rate was 129 beats/min, and oxygen saturation was $80 \%$. Rocuronium $100 \mathrm{mg}$ was injected for muscle relaxation, and intraoperative anesthesia was maintained with 1-1.5 vol\% sevoflurane and $0.5 \mu \mathrm{g} / \mathrm{kg} /$ min remifentanil. To maintain muscle relaxation during surgery, rocuronium was administered every 30 minutes at doses of $30 \mathrm{mg}$. During the operation, oxygen saturation, invasive blood pressure, electrocardiogram, end-tidal $\mathrm{CO}_{2}$ partial pressure and anesthetic gas concentration, body temperature, and bispectral index scale were monitored. Mechanical ventilation was performed in pressure-controlled mode with $100 \%$ oxygen. In the operation room, the patient was ventilated with a peak inspiratory pressure (PIP) of $39 \mathrm{cmH}_{2} \mathrm{O}, 26$ breaths/min, and positive end expiratory pressure (PEEP) of $5 \mathrm{cmH}_{2} \mathrm{O}$. Tidal volume less than $400 \mathrm{ml}$ was achieved and minute ventilation was less than $10 \mathrm{~L} / \mathrm{min}$. The oxygen saturation was $85-90 \%$. Arterial blood gas analysis (ABGA) showed respiratory and metabolic acidosis with hypoxia and hypercapnia, with $\mathrm{pH} 6.85, \mathrm{PCO}_{2} 77 \mathrm{mmHg}, \mathrm{PO}_{2} 73 \mathrm{mmHg}$,

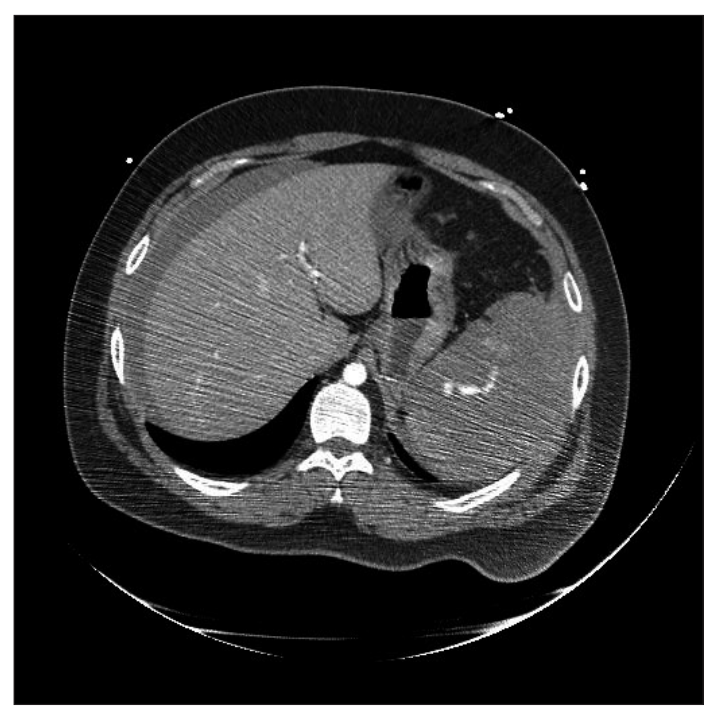

Fig. 1. Abdominal computed tomography image demostrated hemoperitoneum and the American Association for the Surgery of Trauma grade $\mathrm{V}$ spleen injury. and $\mathrm{HCO}_{3}{ }^{-} 13.4 \mu \mathrm{M}$. After laparotomy, tidal volume increased to about $450 \mathrm{ml}$ at $32 \mathrm{cmH}_{2} \mathrm{O}$ of PIP. Minute ventilation was increased to $12 \mathrm{~L} / \mathrm{min}$. The results of ABGA showed slight improvement of hypercapnia and hypoxia with $\mathrm{pH} 7.08, \mathrm{PCO}_{2}$ $61 \mathrm{mmHg}, \mathrm{PO}_{2} 88 \mathrm{mmHg}$, and $\mathrm{HCO}_{3}^{-} 18.1 \mu \mathrm{M}$. Intermittent endotracheal suction and lung recruitment were performed, but PIP, hypoxia, and hypercapnia showed no further improvement. The total operation time was two hours. Approximately 3,300 ml of crystalloid solution was infused, along with transfusion of two units of fresh frozen plasma and one unit of concentrated platelets. Blood loss was about 6,500 ml and total urine output was $95 \mathrm{ml}$. At the end of the operation, the patient's abdomen was closed at the surgeon's direction despite observation of edema of intra-abdominal contents. After the abdominal closure, PIP increased to $41 \mathrm{cmH}_{2} \mathrm{O}$, tidal volume was about $400 \mathrm{ml}$, and respiratory rate was 26 breaths $/ \mathrm{min}$. Minute ventilation was $10.4 \mathrm{~L} / \mathrm{min}$. The patient was transferred to the intensive care unit (ICU) with maintenance of mechanical ventilation.

In the ICU, worsening of hypercapnia and hypoxia was observed, with $\mathrm{pH} 7.1, \mathrm{PCO}_{2} 64 \mathrm{mmHg}, \mathrm{PO}_{2} 53 \mathrm{mmHg}$, and $\mathrm{HCO}_{3}{ }^{-} 21.3 \mu \mathrm{M}$. Chest radiography in the ICU revealed bilateral infiltration of the lungs (Fig. 2). The decision was made to implement VV-ECMO. Because both jugular veins were in use for central venous catheters, cannulation with 21-French and 27-French cannulas (Bio-Medicus Cannula, Medtronic Inc., USA) was performed via the left and right femoral veins.

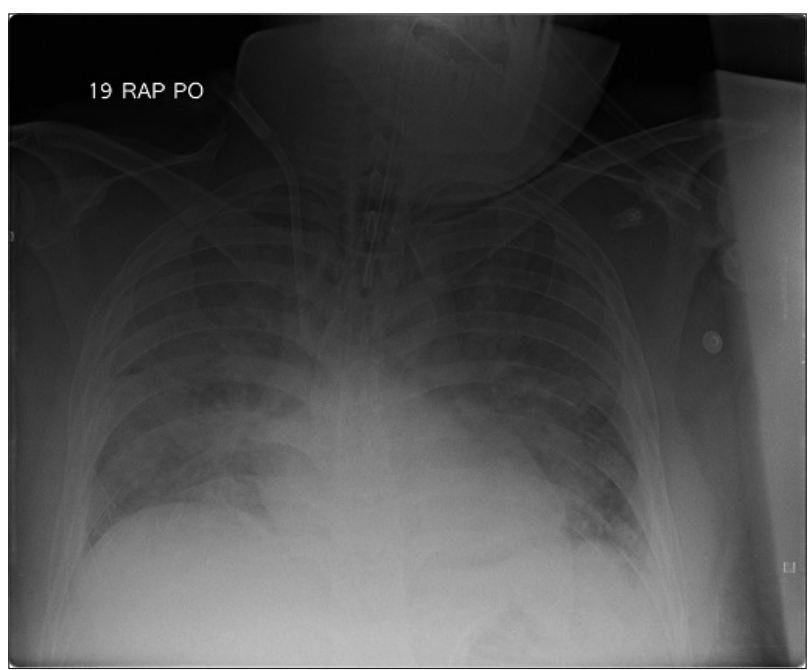

Fig. 2. Chest radiograph after the operation showed bilateral infiltration of lungs. 
The drainage cannula tip was placed in the inferior vena cava (IVC), and the return cannula tip was placed in the right atrium. VV-ECMO (Capiox Emergency Bypass System, EBS, Terumo Inc., Japan) was initiated. Initially, ECMO was applied with $\mathrm{FiO}_{2}$ 1.0, gas flow $5 \mathrm{~L} / \mathrm{min}$, and blood flow $2.9 \mathrm{~L} /$ $\min$.

The ABGA performed immediately after VV-ECMO showed improvement of hypercapnia with $\mathrm{pH} 7.28, \mathrm{PCO}_{2} 34 \mathrm{mmHg}$, and $\mathrm{PO}_{2} 63 \mathrm{mmHg}$. The PIP was reduced from $35 \mathrm{cmH}_{2} \mathrm{O}$ to $30 \mathrm{cmH}_{2} \mathrm{O}$ with $5 \mathrm{cmH}_{2} \mathrm{O}$ of PEEP, and the respiratory rate was reduced from 26 to 20 breaths/min. One day after the ECMO application, arterial blood gas analysis showed an improvement to $\mathrm{pH} 7.35, \mathrm{PCO}_{2} 37 \mathrm{mmHg}, \mathrm{PO}_{2} 92 \mathrm{mmHg}$, and $\mathrm{HCO}_{3}{ }^{-} 20.4 \mu \mathrm{M}$. Chest radiography showed improvement in infiltration (Fig. 3). Serial ABGA results and pulmonary mechanics of the patient are presented in Table 1.

Transthoracic echocardiography in the ICU showed normal left ventricular function. Norepinephrine $0.3 \mu \mathrm{g} / \mathrm{kg} / \mathrm{min}$ was infused before institution of ECMO. During the initiation of ECMO, the patient's blood pressure temporarily dropped to $69 / 50 \mathrm{mmHg}$. However, the blood pressure recovered with infusion of epinephrine $0.2 \mu \mathrm{g} / \mathrm{kg} / \mathrm{min}$ and volume replace- ment. The need for inotropics and vasopressors gradually decreased during the application of ECMO.

Serum creatinine level was increased to $3 \mathrm{mg} / \mathrm{dl}$ on postoperative day 1 . However, urine output was maintained at 1-1.5 $\mathrm{ml} / \mathrm{kg} / \mathrm{h}$ after the operation. Serum creatinine subsequently gradually decreased.

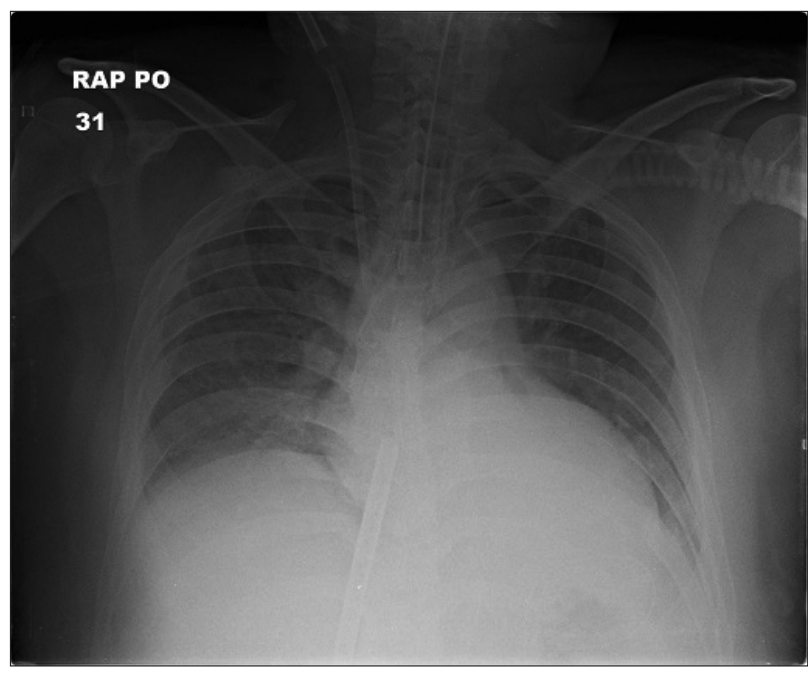

Fig. 3. Chest radiograph one day after extracorporeal membrane oxygenation application showed improved state of lung infiltration.

Table 1. Clinical Course of the Patient after ER Arrival

\begin{tabular}{|c|c|c|c|c|c|c|c|c|c|c|c|c|c|c|}
\hline \multirow{2}{*}{ Variable } & \multicolumn{9}{|c|}{ Approximate time after ER arrival (h' min") } & \multirow{2}{*}{ POD \#1 } & \multirow{2}{*}{ POD \#2 } & \multirow{2}{*}{ POD \#4 } & \multirow{2}{*}{ POD \#6 } & \multirow{2}{*}{ POD \#7 } \\
\hline & $10^{\prime \prime}$ & $2^{\prime}$ & $3^{\prime}$ & 3' 30" & $4^{\prime} 30^{\prime \prime}$ & 5' 30" & 6' $30^{\prime \prime}$ & $9^{\prime}$ & $11^{\prime}$ & & & & & \\
\hline Events & & * & + & & $\neq$ & & $\S$ & & $"$ & & & & "ा & ** \\
\hline $\mathrm{MBP}(\mathrm{mmHg})$ & 67 & 53 & 80 & 91 & 89 & 69 & 68 & 116 & 62 & 88 & 85 & 81 & 76 & 91 \\
\hline $\mathrm{NE}(\mu \mathrm{g} / \mathrm{kg} / \mathrm{min})$ & & 0.2 & 0.3 & 0.2 & 0.1 & 0.2 & 0.2 & 0.3 & 0.4 & 0.6 & 0.5 & 0.3 & & \\
\hline $\mathrm{PIP}\left(\mathrm{cmH}_{2} \mathrm{O}\right)$ & & & 25 & 30 & 36 & 32 & 39 & 40 & 30 & 26 & 21 & 23 & 20 & \\
\hline Tidal volume (ml) & & & 600 & & 350 & 450 & 400 & 400 & 400 & 425 & 450 & 500 & 620 & \\
\hline $\mathrm{C}_{\mathrm{dyn}}\left(\mathrm{ml} / \mathrm{cmH}_{2} \mathrm{O}\right)$ & & & 30 & & 11.3 & 16.7 & 11.7 & 11.4 & 16 & 26.6 & 40.9 & 38.5 & 62 & \\
\hline RR (per min) & & & 15 & & 26 & 26 & 26 & 26 & 20 & 20 & 15 & 18 & 16 & \\
\hline $\operatorname{PEEP}\left(\mathrm{cmH}_{2} \mathrm{O}\right)$ & & & 5 & 5 & 5 & 5 & 5 & 5 & 5 & 10 & 10 & 10 & 10 & \\
\hline $\begin{array}{l}\mathrm{FiO}_{2} \\
\mathrm{ABGA}\end{array}$ & 0.21 & & 1 & 0.5 & 1 & 1 & 1 & 1 & 1 & 0.9 & 0.75 & 0.5 & 0.4 & 0.5 \\
\hline $\begin{array}{c}\mathrm{ABGA} \\
\mathrm{pH}\end{array}$ & 7.41 & & \multicolumn{12}{|c|}{ ABGA } \\
\hline $\mathrm{PaCO}_{2}(\mathrm{mmHg})$ & 28 & & 29 & 47 & 77 & 61 & 62 & 64 & 34 & 37 & 32 & 44 & 44 & 44 \\
\hline $\mathrm{PaO}_{2}(\mathrm{mmHg})$ & 85 & & 224 & 104 & 73 & 88 & 76 & 53 & 63 & 92 & 143 & 131 & 116 & 143 \\
\hline $\mathrm{HCO}_{3}^{-}(\mathrm{mmol} / \mathrm{L})$ & 17.7 & & 15.3 & 13.9 & 13.4 & 18.1 & 19.7 & 21.3 & 16 & 20.4 & 24.4 & 33.4 & 32.8 & 30.6 \\
\hline Hemoglobin (g/dl) & 15.6 & & 6.8 & 8.2 & 10.9 & 13 & 14.6 & 15.8 & 10.9 & 11.2 & 9.9 & 9.5 & 9.6 & 7.4 \\
\hline Lactate (mmol/L) & 4.9 & & 4.3 & 7.9 & 11.4 & 7.4 & 5.5 & 4.1 & 5.2 & 4 & 3.3 & 1.0 & 1.3 & 1.3 \\
\hline Creatinine (mg/dl) & & 1.1 & & & & & & 1.7 & & 3.1 & 2.9 & 1.9 & 1.3 & 1.18 \\
\hline $\mathrm{l} / \mathrm{O}(\mathrm{ml} / 24 \mathrm{~h})$ & & & & & & & & & & 1,379 & -286 & -524 & -668 & -143 \\
\hline
\end{tabular}

ER: emergency room, POD: postoperative day, MBP: mean arteria blood pressure, NE: norepinephrine equivalent dose, PIP: peak inspiratory pressure, $\mathrm{C}_{\text {dyn }}$ : dynamic compliance of lung, RR: respiration rates, PEEP: positive end-expiratory pressure, ABGA: arterial blood gas analysis, I/O: fluid input and output, BP: blood pressure, ECMO: extracorporeal membrane oxygenation. *BP drop, ${ }^{\dagger}$ Intubation, ${ }^{\ddagger}$ Operation start, ${ }^{8}$ Operation end, " ECMO application, "ECMO weaning, **Extubation. 
To avoid pulmonary and visceral edema, we minimized fluid administration and used inotropics and vasopressors when hypotension occurred. With the exception of the first day of ECMO, when priming fluid for ECMO was administered, negative fluid balance was maintained.

Low dose unfractionated heparin was given for systemic anticoagulation. The activated clotting time was maintained between 180-200 seconds during ECMO application. Despite heparinization, the fluid drained from the surgical wound was not bloody, with a volume of less than $350 \mathrm{ml} /$ day, and no significant bleeding was observed.

ECMO was continued for six days. The patient was extubated on the day after weaning off ECMO. Deep vein thrombosis was found in the lower limb on postoperative day 13, and anticoagulant therapy was performed. The patient was discharged from the hospital without any significant complications.

\section{DISCUSSION}

ACS and IAH are caused by abdominal trauma, intraperitoneal lesions, sepsis, and edema due to excessive fluid resuscitation. Risk factors for the development of IAH and/or ACS include acidosis, coagulopathy, sepsis, shock, hypotension, mechanical ventilation, $\mathrm{PEEP}>10 \mathrm{cmH}_{2} \mathrm{O}$, pneumonia, major burns, major trauma, fluid overload, peritonitis, abdominal surgery, obesity, and hemoperitoneum [3].

An increase in the pressure of the abdominal cavity not only affects the perfusion of organs but also affects the respiratory function by compressing the thoracic cavity. IAH causes elevation of the diaphragm, decrease of chest wall compliance, decrease of functional residual capacity, and atelectasis, which result in deterioration of oxygenation and carbon dioxide removal [3].

In this case, $\mathrm{PaO}_{2} / \mathrm{FiO}_{2}$ was less than $200 \mathrm{mmHg}$, bilateral infiltration was observed on chest radiography, and the patient's left ventricular function was normal on transthoracic echocardiography. Therefore, the patient met the diagnostic criteria for acute respiratory distress syndrome (ARDS). In additional to the criteria for ARDS, tidal volume was not achieved owing to excessive airway pressure, and ventilation was worsened with abdominal closure.

The patient was morbidly obese and had multiple risk factors for ACS (multiple trauma, hemoperitoneum, damage control laparotomy, massive fluid resuscitation, mechanical ventilation, and acidosis). Because edema of abdominal contents was observed during the operation and respiratory mechanics worsened abruptly after abdominal closure, we assumed that ARDS with ACS was the cause of respiratory failure, even though the patient's IAP was not measured.

To manage ACS, direct pressure reduction through intraabdominal lesion removal and increasing abdominal wall compliance through neuromuscular blocking agents would be helpful. In addition, adequate perfusion should be maintained while avoiding fluid overload. In severe ACS, open abdomen management can be considered [3].

Most surgeons consider ACS preventable with open abdomen treatment [4]. However, Hatch et al. [5] suggest that damage control laparotomy and open abdomen treatment are being overutilized. Moreover, high levels of evidence regarding open abdomen management are still lacking [6]. Open abdomen by itself is a morbid procedure and has limitations including complications such as enteroatmospheric fistula and ventral hernia, and the requirement for definitive closure [7]. The surgeon in the present case decided to close the abdomen for these reasons.

In patients who cannot maintain oxygenation via mechanical ventilation, extracorporeal oxygenation can provide temporary support for breathing and circulation. There are two main types of ECMO: veno-venous and veno-arterial (VA). While VV-ECMO provides only respiratory support, VAECMO provides hemodynamic support as well as respiratory support. VV-ECMO has a lower risk of bleeding, embolism, acute kidney injury, distal ischemia, and flow competition between the patient's native circulation and ECMO than does VA-ECMO [8-10]. In addition, there have been reports of successful use of VV-ECMO in hemodynamically unstable patients with ARDS $[11,12]$.

There are several concerns related to application of ECMO in a trauma patient with ACS, such as the individual in this case. First of all, there can be concern about bleeding due to the use of heparin. However, there have been several cases in which ECMO was successfully used in trauma patients [13,14]. Furthermore, there was a report suggesting that ECMO improved coagulopathy in a trauma patient [15]. Secondly, disruption of ECMO flow in patients with ACS due to compression of the IVC has been reported $[1,2]$. Although disruption of ECMO flow in femoral cannulation was not observed 
in our patient, the jugular vein may be considered a more suitable cannulation site than the femoral vein for ECMO in patients with ACS. Placement of a double lumen ECMO cannula (Avalon Elite Bicaval Dual Lumen catheter, Avalon Laboratories, LLC, USA) via the right internal jugular vein seems barely affected by IVC compression, and can be considered as a VV-ECMO cannulation strategy in patients with ACS. Thirdly, massive fluid administration to achieve appropriate flow rates in ECMO can aggravate ACS with visceral edema [2]. In such cases, massive fluid was administered to achieve appropriate rates of VA-ECMO to overcome hemodynamic instability. It appears crucial to minimize fluid administration to prevent volume overload when applying ECMO in patients with ACS.

In conclusion, we experienced a case of severe hypoxemia due to ARDS with ACS in a multiple trauma patient, which was successfully improved with VV-ECMO. There are limitations in applying ECMO to patients with ACS and multiple trauma, as previously mentioned. However, considering the potential complications of open abdomen therapy, VVECMO may be an appropriate therapeutic option in cases of pulmonary dysfunction with IAP and/or ACS.

\section{CONFLICTS OF INTEREST}

No potential conflict of interest relevant to this article was reported.

\section{ORCID}

Jun Hyun Kim: https://orcid.org/0000-0002-9466-8399

Sunghyeok Park: https://orcid.org/0000-0001-8604-1716

\section{REFERENCES}

1. Lam MC, Yang PT, Skippen PW, Kissoon N, Skarsgard ED. Abdominal compartment syndrome complicating paediatric extracorporeal life support: diagnostic and therapeutic challenges. Anaesth Intensive Care 2008; 36: 726-31.

2. Augustin P, Lasocki S, Dufour G, Rode J, Karsenti A, Al-Attar N, et al. Abdominal compartment syndrome due to extracorporeal membrane oxygenation in adults. Ann Thorac Surg 2010; 90: e40-1.
3. Malbrain ML, De Laet IE, De Waele JJ, Kirkpatrick AW. Intraabdominal hypertension: definitions, monitoring, interpretation and management. Best Pract Res Clin Anaesthesiol 2013; 27: 249-70.

4. Strang SG, Van Lieshout EM, Verhoeven RA, Van Waes OJ, Verhofstad MH. Recognition and management of intra-abdominal hypertension and abdominal compartment syndrome; a survey among Dutch surgeons. Eur J Trauma Emerg Surg 2017; 43: 8598.

5. Hatch QM, Osterhout LM, Podbielski J, Kozar RA, Wade CE, Holcomb JB, et al. Impact of closure at the first take back: complication burden and potential overutilization of damage control laparotomy. J Trauma 2011; 71: 1503-11.

6. Popivanov G, Kjossev K, Mutafchiyski V. The open abdomen still a challenge for the surgeons. Which is the best technique for temporary abdominal closure? A focus on negative pressure wound therapy. G Chir 2017; 38: 267-72.

7. Huang Y, Li Y. Open abdomen in trauma patients: a doubleedged sword. Mil Med Res 2016; 3: 10.

8. Delius R, Anderson H 3rd, Schumacher R, Shapiro M, Otsu T, Toft K, et al. Venovenous compares favorably with venoarterial access for extracorporeal membrane oxygenation in neonatal respiratory failure. J Thorac Cardiovasc Surg 1993; 106: 329-38.

9. Oshima K, Kunimoto F, Hinohara H, Ohkawa M, Mita N, Tajima $\mathrm{Y}$, et al. Extracorporeal membrane oxygenation for respiratory failure: comparison of venovenous versus venoarterial bypass. Surg Today 2010; 40: 216-22.

10. Papademetriou MD, Tachtsidis I, Banaji M, Elliott MJ, Hoskote A, Elwell CE. Optical topography to measure variations in regional cerebral oxygenation in an infant supported on veno-arterial extra-corporeal membrane oxygenation. Adv Exp Med Biol 2012; 737: 71-6.

11. Gutsche JT, Mikkelsen ME, McCarthy FH, Miano TA, Vernick WJ, Ramakrishna H, et al. Veno-venous extracorporeal life support in hemodynamically unstable patients with ARDS. Anesth Analg 2017; 124: 846-8.

12. Kon ZN, Bittle GJ, Pasrija C, Pham SM, Mazzeffi MA, Herr DL, et al. Venovenous versus venoarterial extracorporeal membrane oxygenation for adult patients with acute respiratory distress syndrome requiring precannulation hemodynamic support: a review of the ELSO registry. Ann Thorac Surg 2017; 104: 645-9.

13. Cordell-Smith JA, Roberts N, Peek GJ, Firmin RK. Traumatic lung injury treated by extracorporeal membrane oxygenation (ECMO). Injury 2006; 37: 29-32.

14. Lisagor P, Cohen D, McDonnell B, Lawlor D, Moore C. Irrevers- 
ible shock revisited: mechanical support of the cardiovascular system: a case report and review. J Trauma 1997; 42: 1182-6.

15. Larsson M, Forsman P, Hedenqvist P, Östlund A, Hultman J, Wik- man A, et al. Extracorporeal membrane oxygenation improves coagulopathy in an experimental traumatic hemorrhagic model. Eur J Trauma Emerg Surg 2017; 43: 701-9. 